\title{
Participação social na coleta seletiva solidária: estudo de caso de uma instituição federal de ensino superior no Brasil
}

\section{Tiago Guterres de Freitas ${ }^{1}$, Sheila Kocourek ${ }^{2}$, Jairo da Luz Oliveira $^{2}$ e Angelica Oliveira de Campos ${ }^{4}$}

\author{
${ }^{1}$ Universidade Federal de Santa Maria. Programa de Pós-Graduação em Gestão de \\ Organizações Públicas. Av. Roraima, 1000. Cidade Universitária. Camobi. Santa \\ Maria-RS, Brasil (CEP 97105-900).E-mail: tiagossocial@hotmail.com. \\ ${ }^{2}$ Universidade Federal de Santa Maria. Departamento de Serviço Social. Programa \\ de Pós-Graduação em Gestão de Organizações Públicas. Av. Roraima, 1000. Cidade \\ Universitária. Camobi. Santa Maria-RS, Brasil (CEP 97105-900). \\ ${ }^{3}$ Prefeitura Municipal de Santa Maria. Rua Venâncio Aires, 2277. Centro. Santa \\ Maria-RS, Brasil (CEP 97010-005).
}

Resumo. Considerando a necessidade de um destino ambientalmente adequado aos resíduos gerados pela própria atividade da administração pública e na busca da promoção da inclusão social dos catadores de materiais recicláveis, o Governo Federal publicou o Decreto no 5.940, de 25 de outubro de 2006, instituindo a separação dos resíduos recicláveis descartados pelos órgãos e entidades da administração pública federal direta e indireta, na fonte geradora, e a sua destinação às associações e cooperativas de catadores de materiais recicláveis. Com isso, estabeleceu-se a coleta seletiva solidária na Administração Púbica Federal, criando a necessidade dos seus órgãos e entidades adequarem-se a essa realidade. Assim, as instituições federais de ensino superior (IFES) têm a responsabilidade de implementar esse modelo de coleta seletiva. Um dos aspectos fundamentais para garantir a sua consolidação da coleta seletiva solidária é a efetiva participação das fontes geradoras. Diante disso, este estudo trata da participação social na coleta seletiva solidária da Universidade Federal de Santa Maria (UFSM), norteando-se pelo seguinte problema "como contribuir com proposições para efetiva participação social na coleta seletiva solidária da UFSM?" A partir disso, objetivou-se analisar a participação social na coleta seletiva solidária da UFSM, tendo em vista contribuir com ações de gestão socioambiental na busca do efetivo envolvimento da comunidade acadêmica, por meio de ações de educação ambiental. Para tanto, foi realizada uma pesquisa survey, a partir de um estudo de caso, com caráter exploratório e uma abordagem quantitativa. 0 instrumento utilizado para obter os dados foi um questionário on line semiestruturado. Como resultados, foi percebido que a comunidade acadêmica compreende que suas ações são importantes para efetivação da coleta seletiva solidária

Recebido

$14 / 02 / 2020$

Aceito

$13 / 06 / 2020$

Disponível on line

$22 / 06 / 2020$

Publicado

$31 / 08 / 2020$

Acesso aberto

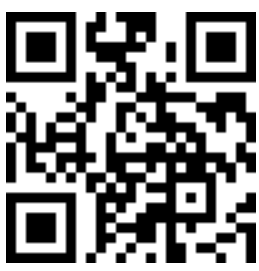

ORCID

(1) 0000-0002-3194-0607 Tiago Guterres de Freitas

() $0000-0001-8962-8758$ Sheila Kocourek

(D) 0000-0002-5006-4614 Jairo da Luz Oliveira

ISSN 2359-1412/RBGAS-2020-0022/2020/7/16/7/553

Rev. Bras. Gest. Amb. Sustent.

http://revista.ecogestaobrasil.net 
e recomece o valor dessa ação para a gestão de resíduos recicláveis na UFSM. Além disso, manifesta preocupação em relação ao quantitativo de resíduos gerados, buscando reduzir o volume desses materiais. Foi possível também observar que a sustentabilidade ambiental com vistas à preservação do meio ambiente, a manutenção do campus limpo e a geração de emprego e renda para os recicladores são os aspectos mais relevantes para motivação da participação social na coleta seletiva solidária. Em contrapartida, identificou-se que o conhecimento insuficiente acerca da coleta seletiva solidária pela comunidade acadêmica e a presença de lacunas nas ações de divulgação e sensibilização são obstáculos para maior e mais efetiva participação social. Baseado nesses achados percebeu-se a necessidade e a relevância da promoção permanente de ações de educação ambiental fortalecendo a informação, sensibilização e mobilização objetivando contribuir para uma maior e mais efetiva participação social na coleta seletiva solidária da UFSM.

Palavras-chave: Decreto Federal no 5.940/2006; Coleta seletiva solidária; Participação Social; UFSM.

\section{Abstract. Social participation in solidary selective collection: case study of a federal higher education institution in Brazil.} Considering the need for an environmentally appropriate destination for the waste generated by the Public Administration's own activity and seeking to promote the social inclusion of waste pickers, the Brazilian Decree No. 5,940, of October 25, 2006, instituting the separation of recyclable waste disposed of by the direct and indirect federal public administration bodies and entities, at the generating source, and its destination to the associations and cooperatives of recyclable material collectors. Thus, the solidary selective collection was established in the federal public administration, creating the need for its organs and entities to adapt to this reality. Thus, federal higher education institutions (IFES) have a responsibility to implement this model of selective collection. One of the fundamental aspects to guarantee its consolidation of the solidary selective collection is the effective participation of the generating sources. Given this, this study deals with social participation in the solidary selective collection of the Federal University of Santa Maria (UFSM), guided by the following problem "how to contribute propositions for effective social participation in the solidary selective collection of UFSM?" From this, the objective was to analyze the social participation in the solidary selective collection of UFSM in order to contribute with actions of socioenvironmental management in the search for the effective involvement of the academic community, through actions of environmental education. Therefore, a survey was conducted, based on a case study, with exploratory character and a quantitative approach. The instrument used to obtain the data was a semi-structured online questionnaire. As a result, it was realized that the academic community understands that their
D) $0000-0001-7769-3333$

Angelica Oliveira de

Campos 
actions are important for the implementation of the solidary selective collection and recommends the value of this action for the management of recyclable waste at UFSM. In addition, it expresses concern regarding the quantity of waste generated, seeking to reduce the volume of these materials. It was also observed that environmental sustainability with a view to preserving the environment, maintaining a clean campus and generating employment and income for recyclers are the most relevant aspects for motivating social participation in the solidary selective collection. On the other hand, it was identified that the insufficient knowledge about the solidary selective collection by the academic community and the presence of gaps in the dissemination and awareness actions are obstacles to greater and more effective social participation. Based on these findings, we realized the need and relevance of the ongoing promotion of environmental education actions, strengthening information, awareness and mobilization aiming to contribute to greater and more effective social participation in the UFSM solidary selective collection.

Keywords: Brazilian Decree N. 5940/2006; Solidary selective collection; Social participation; UFSM.

\section{Introdução}

Na administração pública brasileira, desde o fim dos anos 1990, intensificou-se o estímulo para que os órgãos e as entidades públicas adotem práticas e políticas voltadas à sustentabilidade socioambiental, o que ocorre principalmente por meio do Programa Agenda Ambiental na Administração Pública (A3P) (Luiz et al., 2013). Este programa é uma agenda voluntária, estruturada em eixos temáticos: uso dos recursos naturais, qualidade de vida no ambiente de trabalho, sensibilização dos servidores para a sustentabilidade, compras sustentáveis, construções sustentáveis e gestão de resíduos sólidos (MMA, 2016).

Neste sentido, cada vez mais é necessário que a administração pública, na construção de políticas públicas voltadas ao desenvolvimento sustentável, incorpore princípios de responsabilidade socioambiental nas suas atividades internas e externas. Para tanto, faz-se necessário um planejamento adequado de suas políticas e práticas socioambientais, estimulando mudanças nos investimentos, nas compras e contratações de serviços, passando pela sensibilização e capacitação dos servidores, pela gestão adequada dos recursos naturais utilizados e resíduos gerados, até a promoção da melhoria da qualidade de vida no ambiente de trabalho (Cavalcanti, 2012). Com isso, na busca da promoção dessas diferentes ações na área de responsabilidade socioambiental, entre outros desafios, faz-se necessário o estabelecimento de um sistema de gestão integrada de resíduos sólidos com vistas a manutenção de um ambiente equilibrado e saudável (Ferrari et al., 2015).

Observa-se que, na adoção das políticas e práticas voltadas à gestão dos resíduos sólidos, os órgãos e entidades da Administração Pública Federal devem observar os princípios, objetivos, instrumentos e as diretrizes da Lei no 12.350/2010 (Brasil, 2010), que instituiu a Política Nacional de Resíduos Sólidos (PNRS). Esta lei, que incentiva a não geração, redução, reutilização, reciclagem, bem como a disposição final ambientalmente adequada dos resíduos, apresentando-se como um marco legal-regulatório de transição na 
gestão integrada e sustentável dos resíduos sólidos no Brasil, tem como um de seus principais instrumentos a coleta seletiva (Besen et al., 2014).

Além disso, previamente à PNRS, tendo em vista a necessidade de reforçar o tratamento socioambientalmente correto dos resíduos recicláveis gerados pela sua própria atividade, o Governo Federal já havia instituído a separação dos resíduos recicláveis descartados pelos órgãos e entidades da Administração Pública Federal Direta e Indireta, na fonte geradora, bem como a sua destinação às associações e cooperativas de catadores de materiais recicláveis, através do Decreto no 5.940/2006 (Brasil, 2006).

A partir de então, as Instituições Federais de Ensino Superior (IFES), como os demais órgãos e entidades públicas que têm o desafio do gerenciamento dos diferentes tipos de resíduos gerados no desempenho de suas atividades, na incorporação de práticas sustentáveis no gerenciamento dos resíduos sólidos, entre os quais se encontram os recicláveis, devem observar o estabelecido no Decreto no 5.940/2006 e na Lei 12.305/2010 (Marques et al., 2017).

Com isto, em atendimento ao Decreto no 5.940/2006 e seguindo os princípios, diretrizes e instrumentos da PNRS, compreendendo as demandas por práticas mais sustentáveis e buscando incentivar o tratamento ambientalmente correto aos resíduos recicláveis descartados em seu espaço, a Universidade Federal de Santa Maria (UFSM) deu início, no ano de 2016, ao seu programa de coleta seletiva solidária.

Na implementação desta modalidade de coleta seletiva, assim como nos demais sistemas de coleta seletiva, a sensibilização e a adesão dos responsáveis pela geração dos resíduos são um grande desafio e se constituem em fatores determinantes para sua consolidação. A participação social coloca-se como requisito fundamental para que a coleta seletiva atinja seus objetivos, uma vez que se a fonte geradora não realizar a correta separação e disposição dos resíduos recicláveis, todo o sistema estará comprometido (Bringhenti e Günther, 2011; Beluque et al. 2015).

Este artigo se propõe a analisar a participação social na coleta seletiva solidária da UFSM com fito de contribuir com ações de gestão socioambiental na busca do efetivo envolvimento da comunidade acadêmica, por meio de ações de educação ambiental. Além disso consiste em um aprofundamento do conhecimento no âmbito da coleta seletiva solidária.

Neste sentido a importância da participação social no estabelecimento dos sistemas de coleta seletiva tem relevância no estudo, estando centrada no envolvimento dos cidadãos na separação, disposição e destinação socioambientalmente correta dos resíduos recicláveis descartados no meio ambiente.

\section{Coleta seletiva solidária e a participação das fontes geradoras de resíduos}

Nos órgãos e entidades públicas federais, a prática da coleta seletiva foi institucionalizada e regulamentada a partir do Decreto no 5940/2006, que estabeleceu a modalidade de coleta seletiva solidária (Nascimento et al., 2013).

A implantação da coleta seletiva solidária, que, conforme o art. $2^{\circ}$, inciso I, do Decreto no 5.940/2006 (Brasil, 2006), se traduz na coleta dos resíduos recicláveis descartados, separados na fonte geradora, para destinação às associações e cooperativas de catadores de materiais recicláveis, possibilita que os órgãos e entidades da Administração Federal proporcionem um tratamento e destinação adequados aos resíduos recicláveis gerados pela sua própria atividade, contribuindo assim com a qualidade ambiental e com a melhoria de renda para as famílias dos selecionadores de materiais recicláveis.

Esta modalidade de coleta seletiva introduz um novo modelo de gestão para os resíduos recicláveis no âmbito da Administração Pública Federal Direta e Indireta. Incentiva o tratamento ambiental adequado dos resíduos, através da correta separação, destinação, triagem e reciclagem desses materiais, apresenta-se também como uma 
ferramenta de sensibilização e incentivo à participação da comunidade na gestão socioambiental dos resíduos gerados, além de fortalecer o princípio da inclusão social ao preconizar a destinação dos resíduos às associações e cooperativas dos catadores de materiais recicláveis (Araujo e Altro, 2014).

A partir do Decreto no 5.940/2006 (Brasil, 2006), estabeleceu-se a necessidade dos órgãos e entidades da Administração Pública Federal direta e indireta, dentre as quais se encontram as Instituições Federais de Ensino Superior (IFES), como a Universidade Federal de Santa Maria (UFSM), se adequarem a esse novo sistema de gestão dos resíduos recicláveis que se coloca como uma importante ação que ressalta a responsabilidade socioambiental e fortalece a consciência social e ambiental nos agentes dos órgãos e entidades da administração pública federal.

Neste enquadramento, a Universidade Federal de Santa Maria (UFSM) instituiu em 2016 o seu sistema de coleta seletiva solidária estabelecendo compromisso com as associações de catadores responsáveis pela coleta dos resíduos recicláveis gerados na Instituição. Essa ação reforça o compromisso com a sociedade, com o meio ambiente e com desenvolvimento sustentável, pois visa a proporcionar uma redução dos resíduos encaminhados para coleta convencional prestada pelo município, estimulando a reciclagem, o que contribui para melhorar as condições de trabalho dos catadores, garantindo mais emprego e renda para as famílias envolvidas, fortalecendo com isso a consciência socioambiental na comunidade acadêmica.

Além disto, destaca-se que a coleta seletiva solidária está alinhada ao Plano de Logística Sustentável (PLS) da UFSM, o qual relaciona entre seus objetivos dar um tratamento ambientalmente correto aos resíduos gerados na Instituição. Este objetivo por sua vez está desmembrado em metas que visam fortalecer a gestão de resíduos na Instituição, apresentado como uma de suas ações o incentivo à separação e a redução de geração de resíduos classificados como recicláveis e não recicláveis, por meio de campanhas de conscientização à comunidade acadêmica, valorizando boas práticas (UFSM, 2016).

Por conseguinte, diretamente relaciona-se ao desafio de gestão ambiental estabelecido no Plano de Desenvolvimento Institucional (PDI), 2016-2026 da UFSM, que pauta entre as diretrizes de política ambiental a destinação de resíduos, indicando que as práticas já realizadas nesse sentido devam ser fortalecidas. E, ainda, novas práticas que se fizerem necessárias devem ser incentivadas, como por exemplo, a coleta seletiva solidária (UFSM, 2016).

Neste processo de fortalecimento da coleta seletiva solidária a sensibilização e o engajamento das fontes geradoras são fatores de importância, tendo em vista que quanto maior e mais efetiva a participação social na separação dos resíduos recicláveis, mais eficiente será a coleta seletiva solidária, maior será o ganho econômico, ambiental e social. Dessa forma se garante que um maior volume de resíduos seja reciclado e que mais empregos e mais renda sejam gerados para as famílias dos catadores responsáveis pela triagem e encaminhamento desses materiais para reciclagem.

Tendo em vista que na consolidação dessa gestão sustentável dos resíduos recicláveis a coleta seletiva deve contar com o envolvimento da comunidade de forma ativa e continuada, faz-se necessário desenvolver uma objetiva consciência ambiental, promovendo uma maior mudança de comportamento e em termos de cidadania, pois somente com a participação social ativa a gestão desses resíduos será feita de maneira mais adequada e de forma efetiva (Nogueira, 2014).

Nesse caminho, a Política Nacional de Resíduos Sólidos (PNRS) aponta, entre os seus artigos, a importância de garantir o envolvimento da sociedade civil e, consequentemente, a participação social na gestão dos resíduos (Bicalho e Perreira, 2018). Nesse processo, é preciso fortalecer a mobilização e conscientização popular para transformar a realidade da coleta seletiva e da reciclagem de resíduos, envolvendo as 
fontes geradoras na gestão desses materiais. Para tanto, Gouveia (2012) acena que a ampliação da reciclagem pode ser viabilizada pelo incentivo à coleta seletiva, com adequada separação dos diversos materiais na geração dos resíduos, pela população devidamente informada, e nas centrais de triagem.

Considerando que no processo de implementação de um sistema de coleta seletiva, como a coleta seletiva solidária, o principal fator a ser observado é a participação das fontes geradoras de resíduos, as quais se constituem na força-motriz que irá garantir a efetividade e continuidade desses sistemas, no incentivo à participação social faz necessário o esclarecimento, a sensibilização e a constante mobilização das fontes geradoras para que a coleta seletiva atinja os seus objetivos e se estabeleça ao longo do tempo (Bringhenti e Gunther, 2011).

Alcança-se com isso a dimensão do papel das fontes geradoras no processo de efetivação dos sistemas de coleta seletiva solidária e a necessidade de se garantir a continuidade desses sistemas, para que a política de coleta seletiva atinja os resultados que se espera, tendo em vista que, quanto maior e mais efetiva for a participação social na coleta seletiva solidária maiores serão os benefícios econômicos, ambientais e sociais.

Neste cenário, a educação ambiental vem como instrumento essencial para promover a participação social e, então, a efetividade da coleta seletiva solidária. A educação ambiental, de acordo com a Lei no 9.795/1999 (Brasil, 1999), é um dos processos por meio do qual o indivíduo e a coletividade constroem valores sociais, conhecimentos, habilidades, atitudes e competências voltadas para a conservação do meio ambiente, bem de uso comum do povo, essencial à sadia qualidade de vida e sua sustentabilidade. Nesta construção, os processos de educação ambiental colaboram para formação de uma população organizada, informada, participante e atuante nas questões ambientais (Piccolli et al. 2016).

O desenvolvimento continuado dessas ações de sensibilização e mobilização, através de intervenções de educação ambiental, contribui para evitar o esvaziamento dos sistemas de coleta seletiva solidária incentivando um maior engajamento da comunidade geradora de resíduos. Assegura, com isso, uma maior qualidade e quantidade dos resíduos selecionados, o que reflete em maiores ganhos sociais, econômicos e ambientais (Souza, 2014).

A partir disto, tem-se o fortalecimento das associações e cooperativas de catadores, além de se estabelecer uma maior consciência social e ambiental na sociedade através da promoção da coleta seletiva e da reciclagem.

\section{Procedimentos metodológicos}

Essa pesquisa trata-se de um estudo de caso (Yin, 2015) que apresenta um caráter exploratório, projetando uma maior aproximação com o tema em estudo, além da participação social no sistema de coleta seletiva solidária da Universidade Federal de Santa Maria.

Como estratégia de pesquisa utilizou-se de uma survey. Assim, para a coleta de dados foi realizado um levantamento, tendo em vista que o estudo envolveu uma grande amostra de indivíduos aos quais se procedeu à solicitação de informações acerca do problema de pesquisa em estudo (Gil, 2010). Optou-se pelo método por ser de simples aplicação, com dados confiáveis e análise descomplicada (Malhotra, 2006). Quanto à abordagem, a pesquisa caracteriza-se como quantitativa (Collis e Hussey, 2005).

Traçado esse caminho, para alcançar os resultados propostos foi realizado um estudo de caso com caráter exploratório no campus sede da UFSM, no qual foi realizado um recorte espacial, sendo a coleta de dados realizada no Centro de Ciências Sociais e Humanas (CCSH), maior centro de ensino da Universidade Federal de Santa Maria (UFSM). 
Este estudo englobou três categorias de sujeitos, fontes geradoras de resíduos na Instituição: docentes, técnicos administrativos em educação e discentes. Esses sujeitos fazem parte da comunidade acadêmica da UFSM, todos com vínculo ativo e desempenhando suas atividades no CCSH. Dessa maneira, a população envolvida no estudo foi no total de 4.904 indivíduos, sendo composta por 333 servidores em exercício, dos quais 241 são servidores docentes e 92 servidores técnicos administrativos em educação, além de 4.571 alunos regulares com vínculo ativo presencial.

Considerando a característica numérica da população, composta por um conjunto amplo de indivíduos, foi realizada uma amostragem entre os elementos desse recorte do universo de estudo. Essa formação da amostra estatisticamente representativa, delimitando um grupo satisfatório de pessoas, permite que os resultados possam ser generalizados e aplicados à população (Sampieri et al., 2006). Nesse processo de amostragem considerou-se um erro amostral de 5\% e um nível de confiança de 95\% para uma população finita de 4.904 pessoas. Com isso, o cálculo amostral apontou 357 indivíduos como uma amostra mínima capaz de retratar essa população, sendo comportáveis generalizações.

A coleta de dados se deu através de um questionário estruturado online disponibilizado via Sistema de Questionários da UFSM para as três categorias de sujeitos (tipo senso). Este questionário foi elaborado pelo autor tomando por base os estudos de Bringhenti (2004), Santana (2013) e Vieira (2017). O instrumento de coleta de dados foi composto por 28 questões de escala de Likert (1932), duas questões de múltipla escolha, uma questão aberta e sete questões de reconhecimento de perfil. Para fins de análise as questões foram agrupadas em cinco dimensões: ações dos sujeitos, percepções dos sujeitos, motivações, barreiras e ações da UFSM. Em seguida, somam-se a essas as questões referentes ao perfil.

O questionário foi disponibilizado pelo Centro de Processamento de Dados (CPD) aos sujeitos alvo da pesquisa de forma online, via Sistema de Questionários da UFSM, no período de 28 de maio a 30 de junho de 2019. 0 acesso ao instrumento foi possibilitado através do Portal do RH (Recursos Humanos), Portal do Professor e Portal do Aluno, respectivamente para técnicos administrativos em educação, docentes e discentes.

A consulta ao instrumento de pesquisa foi encerrada no Sistema de Questionários da UFSM às 23:59 h, de 30 de junho de 2019, contabilizando um total de 363 questionários respondidos, atendendo ao quantitativo mínimo da amostra.

Após a coleta dos dados, passou-se à sua análise com o suporte dos softwares Windows Excel 2013 e SPSS (Statistical Package for Social Science) versão 20, que permite a análise de dados a partir de diferentes funções estatísticas, permitindo, entre outras, a determinação de estatísticas descritivas (Field, 2009). Assim, utilizando-se da estatística descritiva, procedeu-se a análise.

Posto isto, na primeira etapa, para traçar o perfil dos respondentes, manipulou-se a ferramenta de analisar estatísticas descritivas no SPSS para utilizar-se das frequências para caracterizar o grupo pesquisado. Em seguida, para descrever as percepções e o comportamento dos sujeitos em relação a cada uma das variáveis, as dimensões estudadas foram examinadas estatisticamente determinando-se as médias e os percentuais para cada uma das questões.

\section{Resultados e discussão}

\section{Análise da amostra}

Com o propósito de caracterizar a amostra organizou-se a Tabela 1, que retrata o perfil dos respondentes em relação às variáveis gênero, categoria, idade, grau de instrução e tempo de vínculo com a UFSM. 
Tabela 1. Perfil dos respondentes segundo as variáveis: gênero, categoria, idade, grau de instrução e tempo de vínculo com a UFSM.

\begin{tabular}{|l|l|c|c|}
\hline Variáveis & \multicolumn{1}{|c|}{ Alternativas } & Frequência & Percentual \\
\hline \multirow{4}{*}{ Gênero } & Feminino & 225 & 62 \\
\cline { 2 - 4 } & Masculino & 138 & 38 \\
\hline \multirow{4}{*}{ Idade } & Discente & 262 & 72,2 \\
\cline { 2 - 4 } & Docente & 45 & 12,4 \\
\cline { 2 - 4 } & Técnico administrativo em educação & 56 & 15,4 \\
\hline \multirow{5}{*}{ Grau de instrução } & Até 30 anos & 195 & 53,7 \\
\cline { 2 - 4 } & De 31 a 50 anos & 134 & 36,9 \\
\cline { 2 - 4 } & Mais de 50 anos & 34 & 9,4 \\
\hline \multirow{5}{*}{ Tempo de vínculo com a UFSM } & Até o ensino médio & 10 & 2,8 \\
\cline { 2 - 4 } & Superior incompleto & 146 & 40,2 \\
\cline { 2 - 4 } & Superior completo & 45 & 12,4 \\
\cline { 2 - 4 } & Especialização & 44 & 12,1 \\
\cline { 2 - 4 } & Mestrado & 40 & 19 \\
\cline { 2 - 4 } & Doutorado & 9 & 11 \\
\cline { 2 - 4 } & Pós-doutorado & 178 & 2,5 \\
\cline { 2 - 4 } & Até 1 ano & 63 & 24 \\
\cline { 2 - 4 } & De 1 a 5 anos & 35 & 9,6 \\
\cline { 2 - 4 } & De Mais de 10 anos & & 17,4 \\
\hline
\end{tabular}

Quanto ao gênero observa-se uma predominância do sexo feminino (62\%). Em relação à idade, identifica-se que há uma maior concentração de indivíduos na faixa etária jovem, com até 30 anos (53,7\%). Ainda em relação aos entrevistados, percebe-se que a maioria está cursando o ensino superior $(40,2 \%)$. No que diz respeito à atuação, a grande maioria da amostra $(72,2 \%)$ foi constituída de discentes. No tocante ao tempo de vínculo, a maior parte dos participantes (49\%) tem um vínculo de 1 a 5 anos com a instituição.

\section{Ações dos sujeitos}

Os aspectos analisados acerca das ações dos sujeitos relacionadas à separação dos resíduos recicláveis e à participação na coleta seletiva solidária foram apresentados na Tabela 2.

Em relação às ações dos sujeitos os dados revelam atitudes propícias ao avanço da coleta seletiva solidária, no entanto alguns pontos precisam ser melhor trabalhados para o seu fortalecimento. Como por exemplo ampliar o esclarecimento e a sensibilização da comunidade acadêmica acerca da sua implementação e operacionalização.

Analisando-se as variáveis separadamente, salienta-se que a grande maioria dos entrevistados, 93,9\%, assinala ter consciência de que suas atitudes são importantes para coleta seletiva solidária e, além de $86,5 \%$ revelarem que suas atitudes contribuem para a redução do volume de resíduos gerados, $66,4 \%$ se colocam como responsáveis pela separação dos resíduos recicláveis que produzem e descartam na UFSM. Essa realidade indica que a parcela comunidade acadêmica estudada está consciente do seu papel como fonte geradora de resíduos e da importância da coleta seletiva solidária para gestão desses materiais na UFSM, além de ter a preocupação com a redução da geração desses materiais. 
Tabela 2. Estatística descritiva das variáveis da dimensão ações do sujeito: média e percentuais.

\begin{tabular}{|c|c|c|c|c|c|c|}
\hline \multirow[b]{2}{*}{ Variável } & \multirow[b]{2}{*}{ Média } & \multicolumn{5}{|c|}{ Percentuais } \\
\hline & & $\begin{array}{l}\text { Discordo } \\
\text { totalmente }\end{array}$ & Discordo & \begin{tabular}{|c|} 
Não \\
concordo e \\
nem \\
discordo \\
\end{tabular} & Concordo & $\begin{array}{l}\text { Concordo } \\
\text { Totalmente }\end{array}$ \\
\hline $\begin{array}{l}\text { Realizo a separação dos } \\
\text { resíduos recicláveis em } \\
\text { minha residência. }\end{array}$ & 3,58 & 12,7 & 12,4 & 8,8 & 36,6 & 29,5 \\
\hline $\begin{array}{lrr}\text { Participo da roleta } \\
\text { seletiva } & \text { solidária } & \text { da } \\
\text { UFSM realizando } & \text { a } \\
\text { separação dos resíduos } \\
\text { recicláveis. }\end{array}$ & 3,17 & 18,7 & 14,0 & 18,2 & 29,2 & 19,8 \\
\hline $\begin{array}{l}\text { Meus colegas participam } \\
\text { da coleta seletiva } \\
\text { solidária da UFSM. }\end{array}$ & 2,89 & 9,1 & 14,6 & 57,0 & 16,8 & 2,5 \\
\hline $\begin{array}{lr}\text { Participo(ei) } & \text { de } \\
\text { atividades de ensino, } \\
\text { pesquisa e/ou extensão } \\
\text { contemplando } \\
\text { temática da gestão de } \\
\text { resíduos na UFSM. }\end{array}$ & 1,79 & 53,2 & 28,9 & 6,9 & 8,3 & 2,8 \\
\hline $\begin{array}{l}\text { Meu comportamento } \\
\text { contribui para redução } \\
\text { da geração de resíduos } \\
\text { na UFSM. }\end{array}$ & 3,72 & 3,3 & 9,6 & 20,7 & 44,6 & 21,8 \\
\hline $\begin{array}{lrr}\text { Sinto-me responsável } \\
\text { pela separação } & \text { dos } \\
\text { resíduos recicláveis por } \\
\text { mim descartados na } \\
\text { UFSM. }\end{array}$ & 4,21 & 0,8 & 3,9 & 8,8 & 46,0 & 40,5 \\
\hline $\begin{array}{l}\text { Penso que minha atitude } \\
\text { é importante para a } \\
\text { coleta seletiva solidária } \\
\text { da UFSM. }\end{array}$ & 4,45 & 0,0 & 0,3 & 5,8 & 42,4 & 51,5 \\
\hline $\begin{array}{lrrr}\text { Conheço } & \text { quais } & \text { são os } \\
\text { tipos de resíduos } \\
\text { recolhidos pela roleta } \\
\text { seletiva solidária da } \\
\text { UFSM. }\end{array}$ & 2,82 & 17,6 & 26,7 & 20,4 & 26,2 & 9,1 \\
\hline $\begin{array}{l}\text { Tenho interesse em } \\
\text { participar de ações de } \\
\text { educação ambiental } \\
\text { voltadas à coleta seletiva } \\
\text { solidária na UFSM. }\end{array}$ & 3,87 & 1,7 & 6,9 & 20,1 & 45,7 & 25,6 \\
\hline
\end{tabular}

No entanto, embora boa parte da amostra, $66,1 \%$, tenha evidenciado que realiza a separação dos resíduos recicláveis em suas residências, especifica-se que o nível de participação da amostra precisa ser melhorado, visto que somente $49 \%$ dos entrevistados indicou participar da coleta seletiva solidária da UFSM e apenas 19,3\% sinalizaram que identificam a participação de seus colegas nesse processo. Sendo assim faz-se necessário o aporte de orientações acerca da execução da coleta seletiva solidária e a intensificação de 
ações contemplando a temática dos resíduos, pelas quais a amostra revela grande interesse, tendo em vista que $71,3 \%$ dos entrevistados se mostraram predispostos a participar de ações de educação ambiental voltadas à coleta seletiva solidária.

Neste caminho, considerando também que 35,3 \% dos entrevistados revelou não conhecer os tipos de resíduos recolhidos pela coleta seletiva solidária e tão somente $11,1 \%$ indicaram que participaram de atividades contemplando a temática da gestão de resíduos, reconhece-se que um ponto a ser trabalhado pelo setor de planejamento ambiental da UFSM é o fortalecimento de ações de educação ambiental acerca da coleta seletiva solidária, esclarecendo e sensibilizando a comunidade acadêmica no sentido de conhecer e aderir ao programa de forma mais clara e efetiva.

\section{Percepções dos Sujeitos}

Seguindo na verificação, exploram-se determinadas questões que relacionam percepções dos sujeitos em relação à gestão dos resíduos recicláveis na UFSM a partir dessa modalidade de coleta seletiva e aos meios disponíveis para recolhimento destes materiais (Tabela 3).

Tabela 3. Estatística descritiva das variáveis da dimensão percepções dos sujeitos: média e percentuais.

\begin{tabular}{|l|l|c|c|c|c|c|}
\hline \multicolumn{1}{|c|}{ Variável } & \multicolumn{5}{|c|}{ Percentuais } \\
\cline { 2 - 6 } & Média & $\begin{array}{c}\text { Discordo } \\
\text { totalmente }\end{array}$ & Discordo & $\begin{array}{c}\text { Não } \\
\text { concordo e } \\
\text { nem } \\
\text { discordo }\end{array}$ & Concordo & $\begin{array}{c}\text { Concordo } \\
\text { Totalmente }\end{array}$ \\
\hline $\begin{array}{l}\text { Tenho preocupação } \\
\text { com a quantidade de } \\
\text { resíduos que produzo } \\
\text { na UFSM. }\end{array}$ & 3,94 & 2,8 & 8,3 & 13,5 & 42,7 & 32,8 \\
\hline $\begin{array}{l}\text { Penso que a separação } \\
\text { dos resíduos } \\
\text { recicláveis é um } \\
\text { problema exclusivo da } \\
\text { gestão da UFSM. }\end{array}$ & 1,60 & 52,9 & 38,6 & 4,4 & 3,6 & 0,6 \\
\hline $\begin{array}{l}\text { Penso que a coleta } \\
\text { seletiva solidária } \\
\text { contribui para a } \\
\text { correta gestão dos } \\
\text { resíduos na UFSM. }\end{array}$ & 4,38 & 0,3 & 1,7 & 6,1 & 44,1 & 47,9 \\
\hline $\begin{array}{l}\text { Os coletores de } \\
\text { resíduos recicláveis } \\
\text { disponíveis no campus } \\
\text { são identificados } \\
\text { facilmente. }\end{array}$ & 2,98 & 9,9 & 29,2 & 21,8 & 31,1 & 8,0 \\
\hline $\begin{array}{l}\text { Identifico os coletores } \\
\text { conforme o tipo de } \\
\text { resíduo a ser } \\
\text { descartado. }\end{array}$ & 3,32 & 8,0 & 17,9 & 21,5 & 39,7 & 12,9 \\
\hline $\begin{array}{l}\text { Os coletores de } \\
\text { resíduos recicláveis } \\
\text { disponíveis no campus } \\
\text { são em número } \\
\text { suficiente. }\end{array}$ & 2,56 & 11,6 & 39,9 & 33,1 & 12,1 & 3,3 \\
\hline
\end{tabular}


Observa-se em relação à percepção dos sujeitos que a maioria da amostra reconhece a contribuição da coleta seletiva solidária para correta gestão dos resíduos na UFSM. Além disso, a maioria dos entrevistados manifesta preocupação com o volume de resíduos produzidos e sente-se responsável pela separação dos resíduos recicláveis. No entanto, identificam-se questões a serem melhoradas para o descarte correto de cada tipo de resíduo. Os dados revelam a importância de se adequar o número de pontos de coleta dos resíduos recicláveis, bem como de se reforçar a identificação dos coletores enfatizando para a comunidade acadêmica a categorização dos resíduos conforme sua composição e seus respectivos coletores.

Analisando as questões associadas às percepções dos sujeitos de forma particular, observa-se a manifestação pela grande maioria dos entrevistados, 92\%, de que a coleta seletiva solidária contribui para o adequado gerenciamento dos resíduos, bem como $91,8 \%$ dos entrevistados sinalizam que essa não se trata de uma questão exclusiva da gestão da instituição. Soma-se a essas questões, de forma também positiva, o fato de que $75,5 \%$ dos respondentes manifesta preocupação quanto ao volume de resíduos que é gerado na UFSM.

Para mais, no caminho do fortalecimento desse sistema, tendo em vista que mais da metade dos entrevistados $(51,5 \%)$ considera o quantitativo de coletores de resíduos recicláveis insuficiente, boa parte $(39,9 \%)$ indica não identificar os coletores de resíduos recicláveis facilmente e $25,9 \%$ acenam não identificar os coletores conforme o tipo de resíduos a ser descarado. Reconhece-se a conveniência de se dedicar ao reforço da identificação e da ampliação dos locais destinados a coleta dos resíduos recicláveis, bem como a elucidação da comunidade acadêmica acerca dos tipos de resíduos recolhidos pela coleta seletiva solidária.

Este contexto permite confirmar o quanto é relevante um constante trabalho de divulgação de informações e de sensibilização da comunidade no sentido de promoção da coleta seletiva solidária, visto que a amostra reconhece a sua importância e acena para o comprometimento com a gestão dos resíduos que são gerados, indicando a disposição de colaborar com o programa. Demanda, para tanto, o aporte de ações voltadas à orientação a respeito dos tipos de coletores e de resíduos alvos da coleta seletiva solidária. Além disso, demanda-se a ampliação dos pontos de coleta com o fortalecimento de sua identificação.

\section{Motivação}

Prosseguindo no estudo, são trabalhados determinados aspectos de motivação da participação dos sujeitos na coleta seletiva solidária da UFSM (Tabela 4).

No que diz respeito às questões relacionadas às motivações, observa-se que $88,9 \%$, considera o fator preocupação com o meio ambiente e $69,9 \%$ o fator geração de emprego e renda como relevantes para sua motivação em participar da coleta seletiva solidária da UFSM. Esse resultado vai ao encontro dos principais propósitos da coleta seletiva solidária implementada nos moldes do Decreto no 5940/2006, que são contribuir para melhoria das condições ambientais, promovendo o adequado descarte dos resíduos, e para melhoria das condições sociais dos catadores de materiais recicláveis, promovendo a dignidade e a inclusão social das famílias beneficiadas pelos programas de coleta seletiva solidária. 
Tabela 4. Estatística descritiva das variáveis da dimensão motivações: média e percentuais.

\begin{tabular}{|c|c|c|c|c|c|c|}
\hline \multirow[b]{2}{*}{ Variável } & \multirow[b]{2}{*}{ Média } & \multicolumn{5}{|c|}{ Percentuais } \\
\hline & & $\begin{array}{l}\text { Discordo } \\
\text { totalmente }\end{array}$ & Discordo & $\begin{array}{c}\text { Não } \\
\text { concordo e } \\
\text { nem } \\
\text { discordo } \\
\end{array}$ & Concordo & $\begin{array}{l}\text { Concordo } \\
\text { Totalmente }\end{array}$ \\
\hline $\begin{array}{l}\text { Participaria, se todos } \\
\text { participassem da coleta } \\
\text { seletiva solidária da } \\
\text { UFSM. }\end{array}$ & 3,31 & 8,8 & 16,3 & 26,7 & 31,4 & 16,8 \\
\hline $\begin{array}{l}\text { A preocupação com o } \\
\text { meio ambiente me } \\
\text { motiva participar da } \\
\text { coleta seletiva solidária } \\
\text { da UFSM. }\end{array}$ & 4,29 & 0,0 & 0,6 & 10,5 & 47,9 & 41,0 \\
\hline $\begin{array}{l}\text { A preocupação com a } \\
\text { geração de emprego e } \\
\text { renda me motiva a } \\
\text { participar da coleta } \\
\text { seletiva solidária da } \\
\text { UFSM. }\end{array}$ & 3,88 & 0,8 & 5,8 & 23,4 & 44,6 & 25,3 \\
\hline
\end{tabular}

Por meio dessas evidências percebe-se que a preocupação com o meio ambiente e com a geração de emprego e renda para os recicladores são fatores fundamentais para motivação da participação social na coleta seletiva solidária da UFSM. Além disso, pode-se inferir que um maior envolvimento dos indivíduos pode ser um fator favorável para a mobilização das fontes geradoras de resíduos, já que 48,2\% dos entrevistados que se envolveria se todos participassem da coleta seletiva solidária. Avançando, correlacionamse aspectos que influenciam na motivação em participar da coleta seletiva solidária (Figura 1).

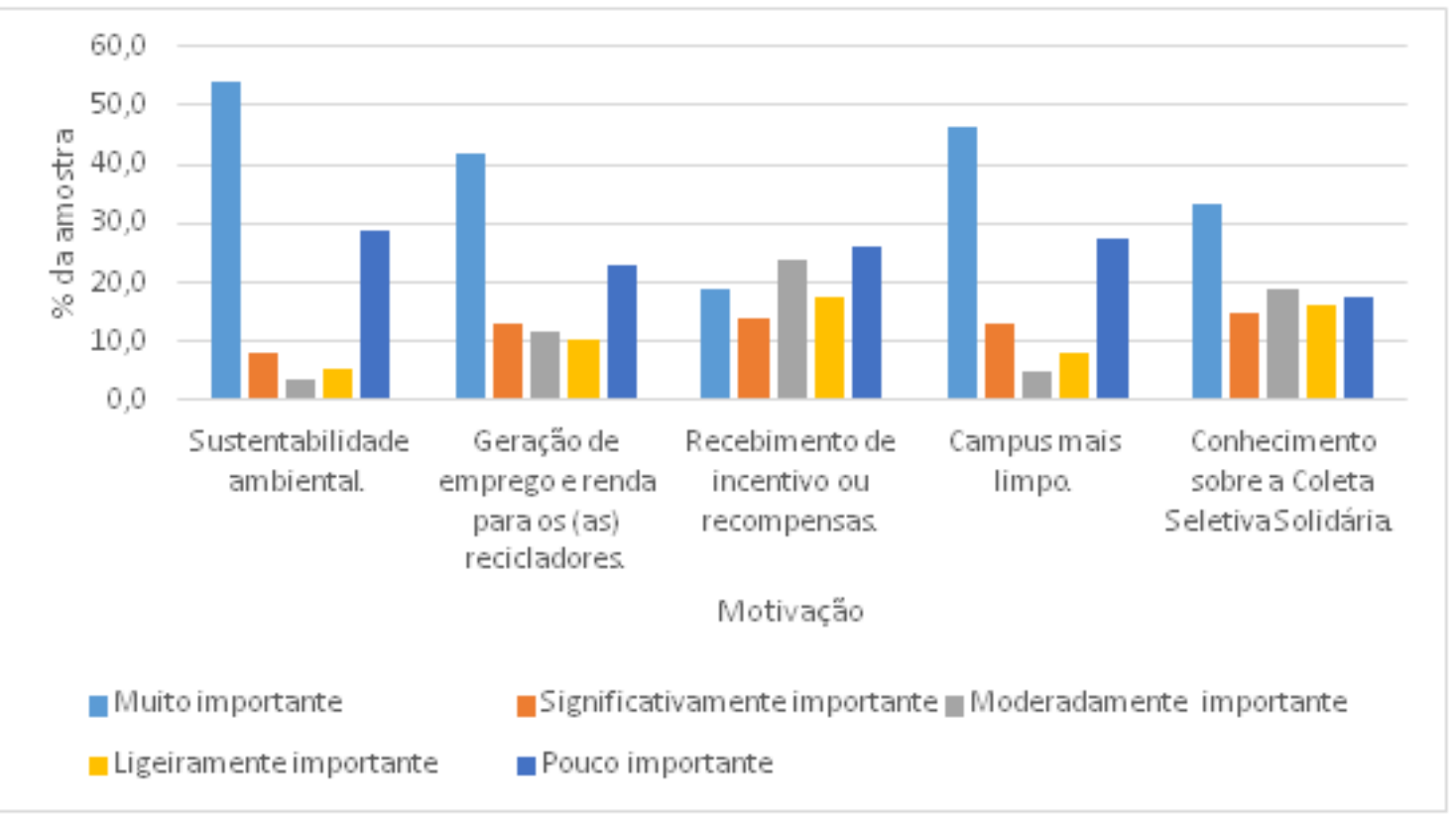

Figura 1. Grau de importância para a motivação em participar da coleta seletiva solidária. 
Confrontando esses aspectos percebe-se que a sustentabilidade ambiental se coloca para os entrevistados como um forte elemento de motivação para participação social na coleta seletiva solidária da UFSM, acompanhada pela preocupação com um campus mais limpo e com a geração de emprego e renda para os (as) recicladores (as). Neves e Castro (2012) também relatam que várias pesquisas apontam a preocupação ambiental como principal motivação para participar de práticas relacionadas com a reciclagem. Além disso, ressaltam o aspecto social ligado à reciclagem gerador de emprego e renda para os recicladores, como motivador da participação social em programas de coleta seletiva.

Tendo em vista que a participação da social é fundamental para a implementação de qualquer programa de coleta seletiva, identificar os aspectos de motivação que levam as pessoas a realizar a separação dos resíduos recicláveis utilizando esses dados em campanhas de educação ambiental, bem como reconhecer as barreiras e trabalhar na sua remoção, assume notável relevância no processo de consolidação dos programas de coleta seletiva (Neves e Castro, 2012).

Finalizando a análise das questões relacionadas às motivações, entende-se a partir dos resultados que o recebimento de incentivo ou recompensas não é um fator significativo como motivador da participação social na coleta seletiva solidária da UFSM. Já a questão ambiental que gira em torno da preocupação com meio ambiente e da sustentabilidade ambiental, a preocupação com um campus mais limpo e a geração de emprego e renda para os(as) recicladores(as) são tidos como fatores importantes na motivação da participação social no processo de separação dos resíduos recicláveis e sua destinação às associações de catadores. Além destes, o conhecimento sobre a coleta seletiva solidária pode ser visto como um fator significativo para a motivação social, o qual contribui para o entendimento de como o participar da coleta.

\section{Barreiras}

Avançando na análise descritiva, investigam-se possíveis barreiras para participação social na coleta seletiva solidária da UFSM (Tabela 5).

Em relação às barreiras, percebe-se que boa parte dos respondentes, 55,6\%, encontra dificuldades para aderir ao sistema, pois informam não saber como participar da coleta seletiva solidária da UFSM. Além disso, há aqueles $(26,6 \%)$ que indicam que esquecem de participar. Contudo, a grande maioria, 89,5\%, sinaliza que acha necessário participar da coleta seletiva. Além disto, $75,8 \%$ dos votantes informam que se sentem motivados para tanto. Destaca-se também que para mais da metade dos entrevistados, 60,6\%, o tempo disponível não é obstáculo para participação na coleta seletiva solidária.

Com isso, percebe-se um cenário favorável para a ampliação da participação social na coleta seletiva solidária, sendo necessário para tanto focar na divulgação e no esclarecimento acerca do modo de operacionalização da coleta seletiva solidária, bem como na constante sensibilização da comunidade acadêmica. Ainda tratando das barreiras, comparam-se os graus de dificuldade que alguns fatores representam para a participação social na coleta seletiva solidária (Figura 2).

Confrontando esses fatores, destaca-se desfavoravelmente o fato de que quase a metade da amostra indicou a falta de conhecimento acerca da coleta seletiva solidária como um item que representa significativa dificuldade para sua participação. Além disso, aponta-se que nessa comparação a amostra se mostrou dividida em relação aos aspectos falta de consciência socioambiental e falta de ações de sensibilização. Já a falta de interesse e a falta de tempo podem ser vistas como questões que representam menor dificuldade para participação em comparação com os demais fatores pautados. 
Tabela 5. Estatística descritiva das variáveis da dimensão barreiras: média e percentuais.

\begin{tabular}{|l|l|l|l|c|c|c|}
\hline \multicolumn{1}{|c|}{ Variável } & Média & Discordo & Discordo & $\begin{array}{c}\text { Não } \\
\text { concordo e } \\
\text { nem } \\
\text { discordo }\end{array}$ & Concordo & $\begin{array}{c}\text { Concordo } \\
\text { Totalmente }\end{array}$ \\
\cline { 2 - 7 } $\begin{array}{l}\text { O tempo que tenho } \\
\text { não me permite } \\
\text { participar da coleta } \\
\text { seletiva solidária da } \\
\text { UFSM. }\end{array}$ & 2,37 & 25,3 & 35,3 & 22,3 & 11,0 & 6,1 \\
\hline $\begin{array}{l}\text { Acho desnecessário } \\
\text { participar da coleta } \\
\text { seletiva solidária da } \\
\text { UFSM. }\end{array}$ & 1,58 & 62,8 & 26,7 & 4,1 & 2,8 & 3,6 \\
\hline $\begin{array}{l}\text { Esqueço de participar } \\
\text { da coleta seletiva } \\
\text { solidária da UFSM. }\end{array}$ & 2,62 & 23,7 & 24,2 & 26,4 & 17,6 & 8,0 \\
\hline $\begin{array}{l}\text { Nada me motiva a } \\
\text { participar da coleta } \\
\text { seletiva solidária da } \\
\text { UFSM. }\end{array}$ & 1,90 & 41,9 & 33,9 & 17,4 & 6,1 & 0,8 \\
\hline $\begin{array}{l}\text { Não sei como } \\
\text { participar da coleta } \\
\text { seletiva solidária da } \\
\text { UFSM. }\end{array}$ & 3,32 & 14,9 & 17,4 & 12,1 & 32,2 & 23,4 \\
\hline
\end{tabular}

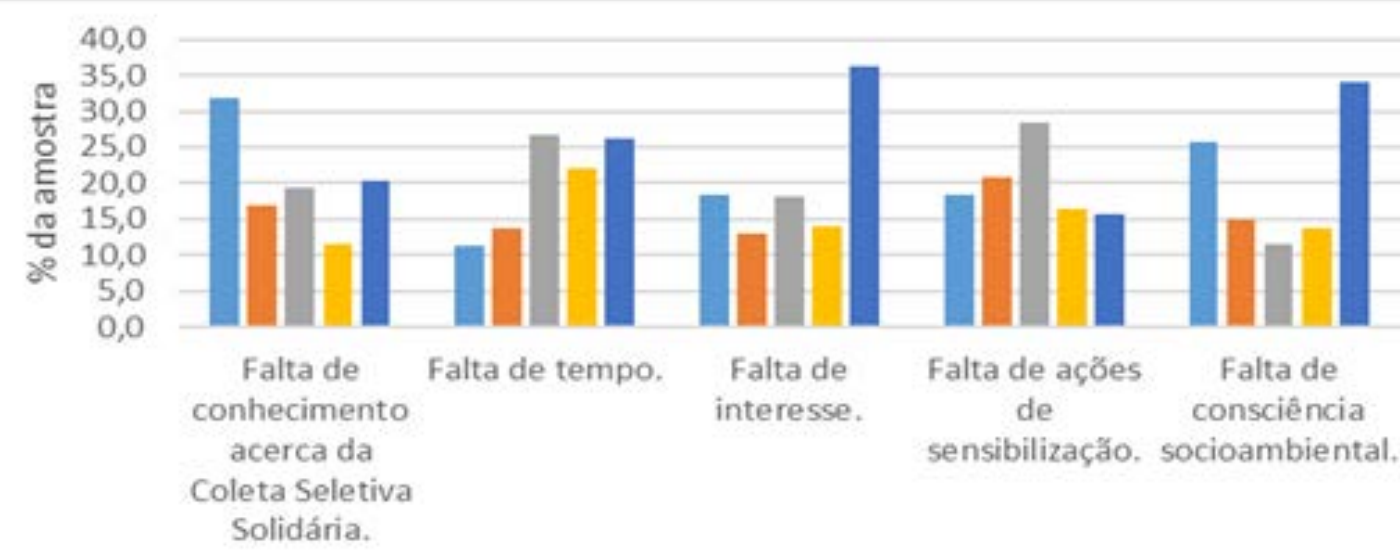

Barreiras

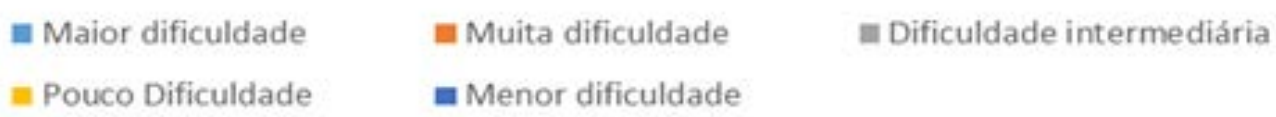

Figura 2. Confrontação dos graus de dificuldade para participação na coleta seletiva solidária.

Contemplando os dados da análise descritiva das variáveis da dimensão barreiras, compreende-se que a falta de interesse pelo tema, de motivação, de tempo e de consciência socioambiental não constituem obstáculos consideráveis para a participação social no processo de separação dos resíduos recicláveis e sua destinação às associações 
de catadores na UFSM. No entanto, há a indicação de que a falta conhecimento acerca da coleta seletiva solidária e de como participar, associadas à carência de ações de sensibilização, constituem-se como barreiras para a inserção efetiva dessa parcela da população na coleta seletiva solidária da UFSM.

Bringhenti e Günther (2011) conferem que a falta de orientação e conhecimento de como participar, associadas à insuficiente divulgação, colocam-se como barreiras da participação social na coleta seletiva, dado que em um estudo sobre a participação social em programas de coleta seletiva de resíduos sólidos urbanos constatou-se que a falta de incentivo, de divulgação e de orientação de como proceder são considerados como fatores impeditivos ou dificultadores da participação da população na coleta seletiva.

Estas circunstâncias indicam a relevância de ser implementado um contínuo trabalho de divulgação de informações e de sensibilização para que a ação de separação e destinação dos resíduos recicláveis para as associações de recicladores não seja esquecida e deixada de lado, enfraquecendo assim a participação social no programa. Além disso, aponta-se a importância de se proporcionar a orientação e capacitação dos envolvidos.

\section{Ações da UFSM}

Encerrada a análise das dimensões, investigam-se aspectos relacionados às ações da UFSM na promoção da coleta seletiva solidária (Tabela 6).

Tabela 6. Estatística descritiva das variáveis da dimensão ações da UFSM: média e percentuais.

\begin{tabular}{|c|c|c|c|c|c|c|}
\hline \multirow[b]{2}{*}{ Variável } & \multirow[b]{2}{*}{ Média } & \multicolumn{5}{|c|}{ Percentuais } \\
\hline & & $\begin{array}{l}\text { Discordo } \\
\text { totalmente }\end{array}$ & Discordo & $\begin{array}{c}\text { Não } \\
\text { concordo } \\
\text { e nem } \\
\text { discordo }\end{array}$ & Concordo & $\begin{array}{l}\text { Concordo } \\
\text { Totalmente }\end{array}$ \\
\hline $\begin{array}{ll}\text { Conheço campanhas de } & \text { sensibilização acerca da } \\
\text { senta } & \text { da } \\
\text { importância } & \text { narticipação social na } \\
\text { coleta seletiva solidária } \\
\text { da UFSM. }\end{array}$ & 2,50 & 18,2 & 37,7 & 24,0 & 15,7 & 4,4 \\
\hline \begin{tabular}{ll}
\multicolumn{2}{l}{ Considero importante a } \\
sensibilização para a \\
coleta seletiva & solidária \\
da UFSM. &
\end{tabular} & 4,53 & 0,3 & 0,0 & 3,3 & 39,4 & 57,0 \\
\hline $\begin{array}{l}\text { Plano de } \\
\text { Desenvolvimento } \\
\text { Institucional (PDI) da } \\
\text { UFSM tem sido } \\
\text { contemplado no que diz } \\
\text { respeito à coleta seletiva } \\
\text { solidária. }\end{array}$ & 3,05 & 1,7 & 8,8 & 75,5 & 11,0 & 3,0 \\
\hline $\begin{array}{l}\text { Há estímulo por parte da } \\
\text { UFSM para participação } \\
\text { social na coleta seletiva } \\
\text { solidária. }\end{array}$ & 2,87 & 6,1 & 25,9 & 45,7 & 19,6 & 2,8 \\
\hline $\begin{array}{l}\text { Gostaria de receber mais } \\
\text { informações sobre a } \\
\text { coleta seletiva solidária } \\
\text { da UFSM. }\end{array}$ & 4,14 & 1,9 & 3,0 & 9,9 & 49,3 & 35,8 \\
\hline
\end{tabular}


No que se refere às ações da UFSM, sobressai o fato de que quase a totalidade da amostra, 96,4\%, considera importante a promoção de ações para o estímulo da coleta seletiva solidária, no entanto mais da metade dos entrevistados, 55,9\%, sinaliza não conhecer ações de sensibilização nesse sentido na UFSM. Além disso, 32\% dos entrevistados aponta que não há estímulo por parte da instituição para participação social na coleta seletiva solidária. Da mesma forma, essa realidade foi apurada por Marques et al. (2017), que em seus estudos também verificou a carência de campanhas contínuas e perspicazes na implantação da coleta seletiva. Neste sentido advertiu-se que a conscientização das pessoas é um grande desafio para gestão da coleta seletiva solidária, demandando programas continuados de sensibilização, preconizando sempre novas ações nesse sentido.

Agora, de forma promissora destaca-se que a grande maioria, 85,1\%, se mostra estimulada a obter mais informações acerca da coleta seletiva solidária. Além disto, refere-se que, em relação às metas do Plano de Desenvolvimento Institucional (PDI), $75,5 \%$ dos entrevistados não se posicionou.

Visto isto, a partir dessa análise pode-se assinalar que a promoção de ações de esclarecimento e sensibilização acerca da importância da participação social na coleta seletiva solidária da UFSM torna-se necessária, necessidade esta no sentido de ampliar e efetivar a participação social no processo de separação e destinação resíduos às associações de recicladores. Corrêa et al. (2015) estudando a participação da população em um Programa de Coleta Seletiva (PCS) mencionam no mesmo sentido ao considerarem que o incremento de ações de informação, sensibilização e esclarecimentos sobre a importância da coleta seletiva empregadas continuamente de forma adequada direciona a uma maior e mais efetiva participação social. Na pesquisa realizada por Salgado et al. (2013), avaliando a coleta seletiva realizada em uma instituição de ensino superior, também foi verificado que ações de divulgação são fundamentais para a sua disseminação e sucesso, uma vez que sua eficiência está ligada diretamente à educação ambiental do público envolvido.

Com isso, na busca do maior e mais efetivo envolvimento da comunidade acadêmica no processo de separação dos resíduos recicláveis e sua destinação às associações e cooperativas de catadores cadastradas, a seguir são propostas ações para subsidiar práticas de educação ambiental objetivando reforçar a participação social no Sistema de coleta seletiva solidária da UFSM.

\section{Propostas de ações}

A elaboração dessas proposições observou a análise dos resultados apresentada nos itens antecedentes, levando em consideração principalmente as percepções e os aspectos de motivação e as barreiras apresentadas pela amostra para a participação no processo de separação dos resíduos recicláveis e sua destinação às associações de selecionadores cadastradas. Ressalta-se que, embora a coleta de dados tenha sido realizada em um recorte da comunidade da UFSM, ou seja, com os sujeitos vinculados ao $\mathrm{CCSH}$, as propostas de ações são direcionadas à comunidade acadêmica como um todo, visto que a coleta seletiva solidária é um programa estabelecido em toda a UFSM.

Neste caminho, as análises apresentadas apontaram que se faz necessário o aporte de ações que proporcionem aos indivíduos um maior contato com informações acerca da implementação, bem como do modo de operacionalização dessa modalidade de coleta seletiva, sensibilizando e instruindo a comunidade acadêmica com vistas a aproximá-la da coleta seletiva solidária. Além disso, embora não tenha sido objeto de estudo, diretamente, emergiu como demanda da readequação dos pontos de coletas de resíduos recicláveis, tanto no que se refere à quantidade dos coletores, bem como à sua devida identificação.

Isto posto, projetou-se propor a realização de um trabalho permanente centrado em dois eixos: o primeiro centrado na divulgação e sensibilização, e outro voltado para a 
capacitação dos sujeitos. 0 primeiro eixo tem como escopo que as pessoas, além de informadas, se sintam envolvidas e responsáveis pelo processo de separação dos resíduos. Já a capacitação objetiva o aprofundamento de conhecimentos acerca da gestão de resíduos, na qual a coleta seletiva é central, de modo a formar multiplicadores dessa temática.

Com isto, as intervenções sugeridas objetivam divulgar informações sobre a coleta seletiva, sensibilizar e melhor preparar os indivíduos com intuito de consolidar a coleta seletiva solidária na rotina da comunidade acadêmica e, por fim, estimular a mudança de comportamento na busca da ampliação da participação social e da constituição de propagadores de boas práticas da gestão de resíduos.

Estas propostas de ações sintetizadas na Tabela 7 vão ao encontro do que foi colocado por Campos et al. (2019), que, ao avaliarem a influência de uma intervenção educacional na eficiência de um programa de coleta seletiva, constaram que a comunidade acadêmica atende positivamente a ações de educação ambiental voltada para a temática de resíduos, melhorando significativamente a segregação desses materiais, sendo essas atividades educacionais permanentes a fim de evitar o decréscimo da participação com passar do tempo.

Tabela 7. Resumo do plano de intervenções.

\begin{tabular}{|c|c|}
\hline Eixo & Propostas de ações a serem desenvolvidas \\
\hline $\begin{array}{l}\text { Divulgação } \\
\text { sensibilização }\end{array}$ & $\begin{array}{l}\text { Compartilhar um informativo digital para orientação e sensibilização } \\
\text { da comunidade universitária; } \\
\text { Inserir materiais educativos e de comunicação nas das mídias sociais, } \\
\text { nos instrumentos e programas de comunicação institucionais; } \\
\text { Fomentar as atividades educativas para os servidores e estudantes nos } \\
\text { encontros, seminários, palestras e demais atividades institucionais } \\
\text { voltadas a essas categorias. } \\
\text { Envolver a comunidade de forma geral, através da promoção de } \\
\text { atividades educativas, culturais e artísticas. }\end{array}$ \\
\hline Capacitação & $\begin{array}{l}\text { Implementar um programa de capacitação permanente direcionado } \\
\text { àqueles que desejam aprofundar seus conhecimentos e ser um } \\
\text { multiplicador das boas práticas de gestão dos resíduos; } \\
\text { Promover a qualificação dos prestadores de serviços terceirizados, } \\
\text { responsáveis pela limpeza dos setores da UFSM, no que tange ao } \\
\text { recolhimento dos resíduos; } \\
\text { Inserir a temática ambiental voltada à gestão de resíduos nos } \\
\text { programas de ensino em disciplinas complementares nos cursos de } \\
\text { graduação e pós-graduação. }\end{array}$ \\
\hline
\end{tabular}

Esta Tabela 7 traduz caminhos que poderão vir a ser seguidos pela gestão do sistema de coleta seletiva solidária da UFSM na construção de um engajamento cada vez maior e mais efetivo da comunidade no processo de separação e destinação dos resíduos recicláveis para as associações de catadores de materiais recicláveis. Beluque et al (2015) apontam que a participação de todos envolvidos em um programa de coleta seletiva é essencial para que se atinja sua plenitude. Assim sendo é fundamental, para tanto, a realização de ações de educação ambiental contínuas e permanentes sanando todas as dúvidas, promovendo assim a correta separação e destinação dos resíduos.

Este processo informativo e educativo de incentivo, de propagação de conhecimentos e de transformação de comportamento deve ser mantido de forma 
permanente para que a comunidade acadêmica consolide um sentimento de cidadania e de pertencimento, favorecendo a sua adequada intervenção na gestão dos resíduos recicláveis e dos demais recursos naturais. Logo, busca-se propiciar com isso o enraizamento de atitudes sustentáveis a nível local que contribuam com a agenda global de desenvolvimento sustentável, estabelecendo a Universidade como modelo de gestão dos resíduos à sociedade, difundindo conhecimento e contribuindo com exemplos práticos de desenvolvimento sustentável.

\section{Considerações finais}

A partir dos resultados alcançados na pesquisa, fazendo-se um apanhado das manifestações dos entrevistados, alcança-se que os indivíduos da amostra, em sua maioria, veem suas ações como importantes para o contexto da coleta seletiva solidária da UFSM e se colocam como responsáveis pelos resíduos que descartam na instituição, revelando inclusive que têm preocupação em reduzir os volumes daquilo que é gerado.

Assinalam também a importância da coleta seletiva solidária para a gestão dos resíduos na UFSM. À vista disso, apontam a preocupação com sustentabilidade e as questões ambientais, com um campus mais limpo, com a geração de emprego e renda para os(as) recicladores e o conhecimento sobre a coleta seletiva solidária como aspectos relevantes para o engajamento da comunidade acadêmica no processo de separação e coleta dos resíduos recicláveis. Por outro lado, indicam a carência de ações de sensibilização e a falta de conhecimento acerca da coleta seletiva solidária e de como participar da ação como fatores impeditivos ou limitadores para a construção de uma maior e mais efetiva participação social.

Complementa-se que, mesmo com o reconhecimento e entendimento exposto acerca da importância da coleta seletiva solidária da UFSM, o que motiva a sua continuidade e o seu fortalecimento, a fração da comunidade acadêmica investigada revelou que é necessário ampliar a adesão e consolidar a participação social no programa. Para tanto, a identificação realizada dos fatores de motivação, bem como das barreiras, se coloca como uma ferramenta fundamental para traçar propostas de ações de educação ambiental na busca de um maior e mais efetivo envolvimento da comunidade acadêmica.

Com isso, objetivando contribuir na construção de uma maior e mais efetiva participação social no processo de separação dos resíduos recicláveis e sua destinação às associações de catadores de materiais recicláveis na UFSM, foram traçados dois eixos de ação, divulgação e sensibilização, além da capacitação dos envolvidos, na busca do fortalecimento dos aspectos de motivação e romper as barreiras. No que tange à divulgação da coleta seletiva solidária e à sensibilização da comunidade acadêmica como ação principal foi proposta a confecção e distribuição de um informativo digital para orientação da comunidade universitária. Além disso, foi indicado fortalecer a inserção da temática da coleta seletiva solidária nas mídias sociais, nos instrumentos e programas de comunicação institucionais, bem como propagar informações e conhecimentos acerca da temática nos encontros, seminários e palestras voltados para servidores e alunos.

Em relação à capacitação, a proposta principal foi a promoção de um programa permanente voltado aos servidores e estudantes interessados em aprofundar e disseminar o conhecimento a respeito da coleta seletiva solidária. Sugeriu-se também a promover a qualificação dos prestadores de serviços terceirizados. Além disso, houve a indicação da inserção da temática nos planos de ensinos de disciplinas complementares ofertadas aos acadêmicos.

Acredita-se que a implementação dessas ações propostas poderá contribuir para ampliar e tornar mais efetiva a participação social na coleta seletiva solidária da UFSM, proporcionando que um maior volume de resíduos seja separado, acondicionado, coletado e destinado de forma adequada às associações cadastradas. 
Em que pese os limites deste estudo, pode-se dizer que a participação de cada cidadão é importante, repensando sua forma de consumo, diminuindo materiais nocivos ao meio ambiente, reduzindo os desperdícios, reutilizando os materiais e descartando os resíduos de forma adequada e reciclando-os. Por meio deste estudo, verificou-se que um dos caminhos para se chegar a esse envolvimento é a permanente promoção de ações de educação ambiental revigorando constantemente a informação, sensibilização e mobilização com vistas de manter e ampliar adesão social. Na UFSM quanto a isso há uma boa expectativa, uma vez que a maioria dos entrevistados no estudo se coloca disposta a participar e receber mais informações acerca da coleta seletiva solidária.

\section{Conflito de interesses}

Os autores declaram não haver conflito de interesses.

\section{Referências}

Araujo, F. O.; Altro, J. L. S. Análise das práticas de gestão de resíduos sólidos na escola de engenharia da Universidade Federal Fluminense em observância ao Decreto 5.940/2006 e à Lei 12.305/2010. Revista Eletrônica Sistemas \& Gestão, v. 9, n. 3, p. 310-326, 2014.

Beluque, A.; Bosco, T. C. D.; Prates, K. V. M. C.; Bonfante, M. C.; Sudo, C. H. Percepções sobre a coleta seletiva solidária na UFPR Câmpus Londrina. Revista Brasileira de Educação Ambiental, v. 10, n. 1, p. 146-163, 2015. https://doi.org/10.34024/revbea.2015.v10.1924

Besen, G. R.; Ribeiro, H.; Günther, W. M. R; Jacobi, P. R. Coleta seletiva na Região Metropolitana de São Paulo: impactos da Política Nacional de Resíduos Sólidos. Revista Ambiente \& Sociedade, v. 17, n. 3, p. 259-278, 2014. https://doi.org/10.1590/S1414753X2014000300015

Bicalho, M. L.; Pereira, J. R. Participação social e a gestão dos resíduos sólidos urbanos: Um estudo de caso de Lavras (MG). Revista Gestão \& Regionalidade, v. 34, n. 100, p. 183201, 2018. https://doi.org/10.13037/gr.vol34n100.2968

Brasil. Lei no 9.795, de 27 de abril de 1999. Dispõe sobre a educação ambiental, institui a Política Nacional de Educação Ambiental e dá outras providências. Disponível em: <http://www.planalto.gov.br/cciviL_03/LEIS/L9795.htm>. Acesso em: 20 jan. 2020.

Brasil. Decreto no 5.940, de 25 de outubro de 2006. Institui a separação dos resíduos recicláveis descartados pelos órgãos e entidades da administração pública federal direta e indireta, na fonte geradora, e a sua destinação às associações e cooperativas dos catadores de materiais recicláveis, e dá outras providências. Disponível em: <http://www.planalto.gov.br/ccivil_03/_Ato2004-2006/2006/Decreto/D5940.htm>.

Acesso em: 18 jan. 2020.

Brasil. Lei no 12.305, de 2 de agosto de 2010. Institui a Política Nacional de Resíduos Sólidos; altera a Lei no 9.605, de 12 de fevereiro de 1998; e dá outras providências. Disponível em: <http://www.planalto.gov.br/ccivil_03/_Ato20072010/2010/Lei/L12305.htm>. Acesso em: 09 jan. 2020.

Bringhenti, J. Coleta seletiva de resíduos sólidos urbanos: aspectos operacionais e da participação da população. São Paulo: Universidade de São Paulo, 2004. (Tese de doutorado).

Bringhenti, J. R.; Gunther, W. M. R. Participação social em programas de coleta seletiva de resíduos sólidos urbanos. Engenharia Sanitária e Ambiental, v. 16, n. 4, p. 421-430, 2011. https://doi.org/10.1590/S1413-41522011000400014 
Campos, A. C. M.; Ribeiro, A. G. C.; Pires, M. C.; Sousa, F. A. Avaliação da influência de atividades de Educação Ambiental na melhoria da coleta seletiva em uma instituição de ensino. Revista Brasileira de Educação Ambiental, v. 14, n. 1, p. 456-477, 2019. https://doi.org/10.34024/revbea.2019.v14.2592

Cavalcanti, M. L. S. A. Administração Pública e Agenda Ambiental - A3P - Considerações sobre a implementação nos órgãos público. Revista Controle: Doutrinas e Artigos, v. 10, n. 1, p. 193-216, 2012.

Collis, J.; Hussey, R. Pesquisa em Administração: um guia prático para alunos de graduação e pós-graduação. 2. ed. Porto Alegre: Bookman, 2005.

Corrêa, L. B.; Hernandes, J. C.; Santos, C. V.; Santos, W. M.; Colares, G. S.; Corrêa, E. K. Análise social de um Programa de Coleta Seletiva de Resíduos Sólidos Domiciliares. Revista Monografias Ambientais, v. 14, n. 2, p. 193-201, 2015.

Ferrari, M. V. D.; Luz M. L. A.; Zaneti, I. C. B. B.; Soares, P. M.; Tavares, D. V. Desafios à gestão de resíduos em IES pública: estudo de caso na Universidade de Brasília - campus Darcy Ribeiro. Revista Interdisciplinar de Pesquisa em Engenharia, v. 1, n. 2, 2015. https://doi.org/10.26512/ripe.v1i2.14441

Field, A. Descobrindo a estatística usando o SPSS. 2. ed. Porto Alegre: Artmed, 2009.

Gil, A. C. Como elaborar projetos de pesquisa. 5. ed. São Paulo: Atlas, 2010.

Gouveia, N. Resíduos sólidos urbanos: impactos socioambientais e perspectiva de manejo sustentável com inclusão social. Revista Ciência \& Saúde Coletiva, v. 17, n. 6, p. 1503-1510, 2012.

Likert, R. A technique for the measurement of attitudes. Archives of Psychology, n. 140, p. 1-55, 1932. Disponível em: <https://legacy.voteview.com/pdf/Likert_1932.pdf>. Acesso em: 14 ago. 2019.

Luiz, L. C.; Rau, K.; Freitas, C. L.; Pfitscher, E. D. Agenda Ambiental na Administração Pública (A3P) e práticas de sustentabilidade: estudo aplicado em um Instituto Federal de Educação, Ciência e Tecnologia. Revista Administração Pública e Gestão Social, v. 5, n. 2, p. 54-62, 2013.

Malhotra, N. K. Pesquisa de marketing: uma orientação aplicada. 4. ed. Porto Alegre: Bookman, 2006.

Marques, E. A. F.; Vasconcelos, M. C. R. L.; Guimarães, E. H. R.; Barbosa, F. H. F. Gestão da coleta seletiva de resíduos sólidos no campus Pampulha da UFMG: desafios e impactos sociais. Revista de Gestão Ambiental e Sustentabilidade, v. 6, n. 3, p. 131-149, 2017.

MMA - Ministério do Meio Ambiente. Cartilha A3P: como implantar a A3P. 2. ed. rev. e atual. Brasília: MMA, 2016 Disponível em: <http://www.mma.gov.br/images/ arquivo/80063/cartilha completa A3P_.pdf>. Acesso em: 22 jan. 2020.

Nascimento, R. O.; D’Aquino, G. I. R.; Mendes, A. C.; Ruivo, M. L. P.; Tashiro, L. H. Coleta seletiva solidária: uma experiência desenvolvida no Campus de Pesquisa do Museu Paraense Emílio Goeldi (MPEG), Belém-PA. Revista Eletrônica em Gestão, Educação e Tecnologia Ambiental, v. 10, n. 10, p. 2233-2250, 2013. https://doi.org/10.5902/ 223611707889

Neves, A. C. R. R.; Castro, L. O. A. Separação de materiais recicláveis: panorama no Brasil e incentivos à prática. Revista Eletrônica em Gestão, Educação e Tecnologia Ambiental, v. 8, n. 8, p. 1734-1742, 2012. https://doi.org/10.5902/223611706631 
Nogueira, C. F. A. Política Nacional de Resíduos Sólidos, coleta seletiva e seus atores: o caso do Distrito Federal. Revista Brasileira de Direito, v. 10, n. 1, p. 106-115, 2014. https://doi.org/10.18256/2238-0604/revistadedireito.v10n1p106-115

Piccoli, A. S.; Kligerman, D. C.; Cohen, S. C.; Assumpção, R. F. A educação ambiental como estratégia de mobilização social para o enfrentamento da escassez de água. Revista Ciência e Saúde Coletiva, v. 21, n. 3, p. 797-808, 2016.

Salgado, C. C. R.; Batista, L. M.; Aires, R. F. F. Coleta seletiva e participação social: a percepção discente da Universidade Federal do Rio Grande do Norte-UFRN. Revista Interface, v. 10, n. 2, p. 130-144, 2013.

Sampieri, R. H.; Collado, C. F.; Lucio, P. B. Metodologia de pesquisa. São Paulo: McGrawHill, 2006.

Santana, H. C. Percepção, motivações e barreiras dos moradores para participação em programas de coleta seletiva de resíduos sólidos domiciliares na Microrregião de Ouro Preto (MG). Ouro Preto: Universidade Federal de Ouro Preto, 2013. (Dissertação de mestrado).

Souza, V. O. Educação Ambiental na efetivação de práticas ecológicas: um estudo de caso sobre práticas ecológicas e coleta seletiva na Universidade Estadual da Paraíba. Revista Brasileira de Educação Ambiental, v. 9, n. 2, p. 364-375, 2014. https://doi.org/ 10.34024/revbea.2014.v9.1840

UFSM - Universidade Federal de Santa Maria. Plano de Logística Sustentável da UFSM (2016-2018). Santa Maria: UFSM, 2016. Disponível em: <https://www.ufsm.br/wpcontent/uploads/2018/08/Plano-de-Logística-Sustentável-2016-2018.pdf>. Acesso em: 22 jan. 2020.

Vieira, L. R. S. Limites e possibilidades da coleta seletiva na Universidade Federal de Uberlândia: um estudo de caso. Uberlândia: Universidade Federal de Uberlândia, 2017. (Dissertação de mestrado).

Yin, R. K. Estudo de caso: planejamento e métodos. 5. ed. Porto Alegre: Bookman, 2015.

Informação da Licença: Este é um artigo Open Access distribuído sob os termos da Licença Creative Commons Attribution, que permite uso irrestrito, distribuição e reprodução em qualquer meio, desde que a obra original seja devidamente citada. 